\title{
Effects of COVID-19 on non- communicable diseases and reproductive health services in a district hospital of Nepal
}

\author{
Rajan Ghimire ${ }^{1 *}$ and Sugat Adhikari² \\ ${ }^{1}$ Clinical Coordinator, District Hospital, Terhathum, Province-1, Nepal \\ ${ }^{2}$ Medical Officer, District Hospital, Terhathum, Province-1, Nepal
}

Received: 27 August, 2020

Accepted: 02 September, 2020

Published: 03 September, 2020

*Corresponding author: Rajan Ghimire, Clinical Coordinator, District Hospital, Terhathum, Province-1, Nepal, Tel: +977 9849807768;

E-mail: biplawi.shashi@gmail.com

ORCID: https://orcid.org/0000-0001-5095-8477

Keywords: COVID-19; Pandemic; Non-communicable disease; Reproductive health

https://www.peertechz.com

Check for updates

\section{Abstract \\ COVID-19 pandemic has an impact on the socio-economic, cultural, and health of people. There is increased morbidity if a patient with comorbidities (hypertension, diabetes) is infected with SARS-CoV 2. On the other hand, there are increased complications related to hypertension, diabetes, and unwanted pregnancies during this pandemic. We did a retrospective study in a district hospital in Nepal to see this effect. We found that there was an increased incidence of uncontrolled diabetes, hypertension, and safe abortions. So while making plans for overall health during this pandemics, proper management of non-communicable diseases and reproductive health services should be considered.}

\section{Abbreviations}

ANC: Antenatal Care; COVID-19: Coronavirus Disease 19; DM: Diabetes Mellitus; nCoV: novel Coronavirus; OCP: Oral Contraceptive Pills; PCR: Polymerase Chain Reaction; SARS$\mathrm{CoV} 2$ : Severe Acute Respiratory Syndrome Coronavirus 2

\section{Introduction}

The start of the journey through this COVID-19 pandemic was not smooth for us. It was not easier for every country in the world. But the developing and resource-poor nations like Nepal have different challenges than developed nations. First of all, the health care system is not well equipped to support the disaster-related to infectious disease epidemics. We lack adequate and quality personal protective equipment. Our laboratory service was not equipped to detect coronavirus and we had only a handful of PCR machines. It took time to arrange PCR machines and train the skilled manpower to use it. There was just a lab with PCR facility throughout the nation during the first case detection in the country. Now, this number has increased to more than twenty. Case detection, confirmation, prevention of disease spread, and treatment are all challenging.
Despite all the shortcomings, every nation is struggling to overcome this pandemic.

This pandemic has affected every sector of society viz. economy, transport, industries, social relations, and health of course. Besides the direct effect of COVID-19, it has affected the course of various other diseases especially non-communicable diseases and mental illness. Today we are going to discuss briefly how this pandemic had affected the non-communicable diseases (diabetes and hypertension), safe abortion services, and safe motherhood services in one of the district hospitals of Nepal.

District hospital, Terhathum is a primary care 15 bedded hospital located in the eastern part of Nepal. We are providing general medicine, general surgical, basic dental care, and obstetric case management including Cesarean sections. To provide this service we have six medical officers and one General Practitioner. Concerning COVID-19 case management, as per national guidelines, we take care of PCR positive isolated patients with no symptoms or mild symptoms, quarantined patients, suspected symptomatic patients, screen patients using SARS-CoV 2 Rapid diagnostic test kit, and collect 
nasopharyngeal and throat swab for PCR. PCR confirmed cases with moderate to severe symptoms are referred to dedicated COVID-19 hospitals. Despite all hurdles, we continued all the services as usual. There was a change in the service consumption patterns in our center. In this study, we analyzed the change in the pattern of service consumption at our center.

\section{Methodology}

It was a retrospective study. We collected data from the record of patients available in the in-patient department, emergency department, maternal and child health department, and safe abortion services from March to July 2020 i.e since the period of lockdown imposed in the country. We compared the data with the same period of the previous year i.e March to July 2019.

\section{Results}

In a month, we have an average of 85 to 90 patients admitted in the in-patient, and approximately 200 patients admitted in the emergency care. During the COVID-19 period, there was an increase in cases of hypertension and diabetes mellitus requiring admission in comparison to the previous year (Table 1). There is an increased incidence of uncontrolled hypertension and diabetes mellitus during this period in the out-patient section too. On individual conversations with these patients, reasons for this were the inadequate supply of drugs, fear to visit a health facility, erratic diet, and a decrease in physical activity.

In five-month, there was a decrease in both the antenatal checkups and the consumption of contraceptive products. Though the hospital was providing all the services continuously, women did not visit the health facility because of fear of pandemic and confusion of whether the service was continued or not. The reflection of this decrease in ANC visit will be seen later on maternal mortality or child mortality indicators. Another indicator of decrease consumption of contraceptive products was an increase in medical abortion. We found an overall increased abortion rate in comparison to the previous year (91 vs 124). There was an increased rate of both first trimester and second-trimester abortion rates (Table 2).

Table 1: Non-communicable disease incidence in patients of in-patient and emergency care.

Uncontrolled Hypertension Uncontrolled DM Hypertension and DM

Mar-Jul 2019

Mar-Jul 2020

6

Table 2: Comparison of reproductive health indicators during the COVID-19 pandemic with the previous year.

\begin{tabular}{|c|c|c|c|}
\hline \multicolumn{2}{|c|}{ Number of Antenatal Checkup } & Mar-Jul 2019 & Mar-Jul 2020 \\
\hline \multirow{3}{*}{ Contraceptive use } & OCP & 328 & 261 \\
\cline { 2 - 4 } & Depo-Provera & 66 & 63 \\
\cline { 2 - 4 } & Jadelle implants & 63 & 14 \\
\hline \multirow{2}{*}{ Safe abortion services } & First-trimester abortion & 85 & 47 \\
\cline { 2 - 4 } & Second-trimester abortion & 6 & 114 \\
\cline { 2 - 4 } & & & 18 \\
\hline
\end{tabular}

\section{Discussion}

Since the time of COVID-19, there has been a constant increase in mental illness throughout the world. Despite the good global recovery rate, the 2019-nCoV suspected/infected victims have a fear of their lives. Even their families are stressed in fear of the loss of their members [1]. According to a study done in China, anxiety and depression were common among the senior citizens [2]. Similarly, anxiety, depression, and insomnia were common during the COVID-19 pandemic [3]. A narrative review showed an increased incidence of depression, anxiety, and poor sleep quality among elderly who are socially isolated [4]. Virtual connections using internet apps, video chat, telephone, or social support help to reduce these psychiatric issues. The same study recommends increased and supervised physical activity and exercise in senior citizens to improve dynamic balance, muscle strength, better lung function, and decrease disabilities [4]. Female gender, living in urban areas, and previous psychiatric illness history were found as risk factors for anxiety; living in urban areas was found as a risk factor for depression; and female gender, accompanying chronic disease, and previous psychiatric history was found as risk factors for health anxiety [5]. Depression, anxiety, decreased physical activity, and an unhealthy diet during quarantine can be a risk for cardiovascular disease [6].

Stake-holders and community pharmacies can play a crucial role to ensure the continuity of the medicine supply of persons with chronic diseases while promoting social distancing and self-isolation during the pandemic. Community pharmacies can start mobile delivery and courier services to promote doorstep prescription refills and other non-prescription supplies [7]. For monitoring the glucose levels of the diabetic patient admitted in different wards in COVID-19 isolation facilities, a personal continuous glucose monitoring system can be used by the duty health team. These reports can be uploaded to the web and continuously monitored by specialists remotely on a realtime basis. This will ensure the quality of care and decreases exposure of the virus to health care persons [8]. Surveillance system via 24 -hour mobile video conferencing can play a pivotal role in augmenting valuable insights for safeguarding the mental health of citizens and devising short-term as well as a long term national mental health policy [9]. To improve reproductive health-related services, policymakers should recognize it as an essential component of health and declare essential during pandemics. Distribution of contraceptive products in the community during this pandemic can be another solution to decrease the unmet need of contraceptives $[10,11]$.

This pandemic has a multi-sectorial effect on society. It has jeopardized the education system of the globe. Webbased teaching-learning activities are not always possible in developing nations [12]. The fear of the spread of virus is also prevalent among the medical community. To decrease this spread, technology can help a lot. The use of bio-sensors and wearable devices can be used to collect the regular data (body-temperature, electroencephalogram signals, fingertemperature, heart-rate, pupil diameter, galvanic-skin- 
response, and blood pressure) of these persons [13]. The stressed environment leads to chaos and scrambling effects on local and global industries (transportation, entertainment, healthcare, steel) and the stock market [8].

As this study was done in a small health organization, the sample size was not large enough. Before generalizing the research findings, large studies should be done.

\section{Conclusion}

There was an increase in the incidence of uncontrolled hypertension, uncontrolled diabetes, and its complications. There was a decrease in antenatal check-ups and the use of contraceptive products. There was an increase in safe abortion. We need to address these issues while making plans to manage the COVID-19 pandemic.

\section{References}

1. Sharma S, Sharma M, Singh G (2020) A chaotic and stressed environment for 2019-nCoV suspected, infected and other people in India: Fear of mass destruction and causality. Asian J Psychiatr 51: 102049. Link: https://bit.ly/2YUQN15

2. Meng H, Xu Y, Dai J, Zhang Y, Liu B, et al. (2020) Analyze the psychological impact of COVID-19 among the elderly population in China and make corresponding suggestions. Psychiatry Res 289: 112983. Link: https://bit.ly/2DpQxzS

3. Gualano MR, Moro G Lo, Voglino G, Bert F, Siliquini R (2020) Effects of Covid-19 Lockdown on Mental Health and Sleep Disturbances in Italy. Int J Environ Res Public Health 17: 1-13. Link: https://bit.ly/3jGxINw

4. Sepulveda-Loyola W, Rodriguez-Sanchez I, Perez-Rodriguez P, et al. (2020) Impact of Social Isolation Due To Covid-19 on Health in Older People: Mental and Physical Effects and Recommendations. J Nutr Heal Aging. Link:
5. Özdin S, Özdin ŞB (2020) Levels and predictors of anxiety, depression and health anxiety during COVID-19 pandemic in Turkish society: The importance of gender. Int J Soc Psychiatry 66: 504-511. Link: https://bit.ly/3biFcOo

6. Mattioli AV, Puviani MB, Nasi M, Farinetti A (2020) COVID-19 pandemic: the effects of quarantine on cardiovascular risk. Eur J Clin Nutr 74: 852-855. Link: https://go.nature.com/32VkS26

7. Kretchy IA, Asiedu-Danso M, Kretchy JP (2020) Medication management and adherence during the COVID-19 pandemic: Perspectives and experiences from low-and middle-income countries. Res Soc Adm Pharm. Link: https://bit.ly/2EHXbIP

8. Sharma S, Singh G (2020) Prevalence and Global Impact of 2019-nCoV Zoonotic Viruses on China and World: Consequences of Chaotic and Stressed Environment. Int J Comput Appl Inf Technol 12: 333-348. Link: https://bit.ly/2ROIOYB

9. Monga P, Sharma M, Sharma SK (2020) Need of surveillance system to support digital psychological intervention to COVID19 afflicted people in India. Int J Soc Psychiatry. Link: https://bit.ly/2QPOgCJ

10. Cousins S (2020) COVID-19 has "devastating" effect on women and girls Lancet 396: 301-302. Link: https://bit.ly/2EOz58Q

11. Riley T, Sully E, Ahmed Z, Biddlecom A (2020) Estimates of the potentia impact of the COVID-19 pandemic on sexual and reproductive health in lowand middle-income countries. Int Perspect Sex Reprod Health 46: 73-76. Link: https://bit.ly/31Rdt4w

12. Gautam R, Sharma M (2020) 2019-nCoV pandemic: A disruptive and stressful atmosphere for Indian academic fraternity. Brain Behav Immun 88: 948-949. Link: https://bit.ly/3hY8i8A

13. Sharma M, Sharma S, Singh G (2020) Remote monitoring of physical and mental state of 2019-nCoV victims using social internet of things, fog and soft computing techniques. Comput Methods Programs Biomed 196: 1-2. Link: https://bit.ly/3jE9NZT

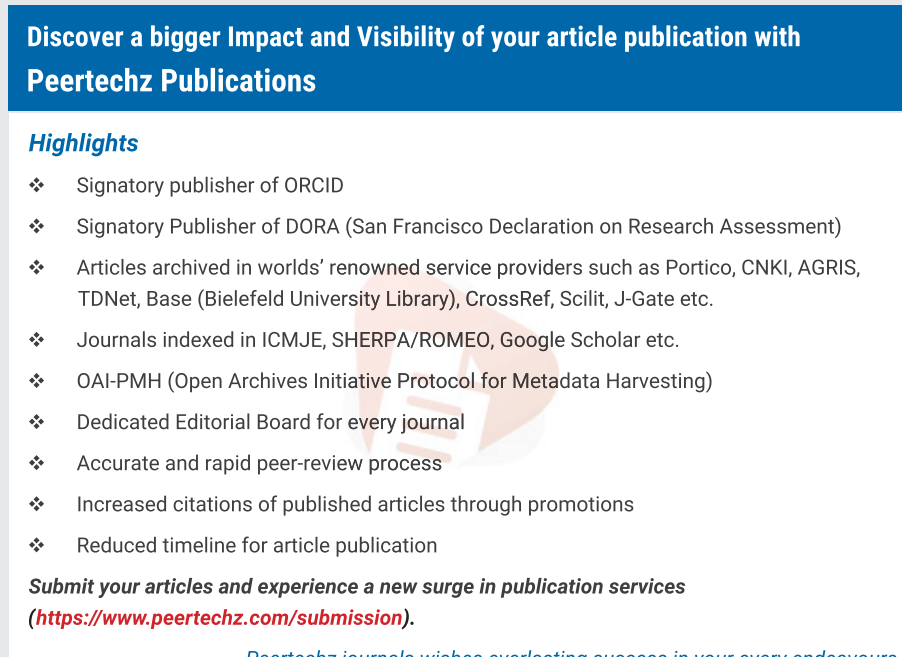

Peertechz journals wishes everlasting success in your every endeavours.

Copyright: @ 2020 Ghimire R, et al. This is an open-access article distributed under the terms of the Creative Commons Attribution License, which permits unrestricted use, distribution, and reproduction in any medium, provided the original author and source are credited. 